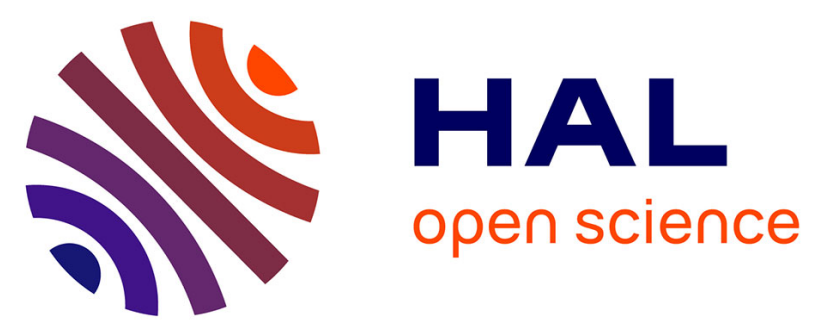

\title{
Detection and quantification of allergens in foods and minimum eliciting doses in food-allergic individuals (Thrall)
}

\author{
E.N. Clare Mills, Karine Adel-Patient, Herve H. Bernard, Marc de Loose,
} Nathalie Gillard, Anne-Catherine Huet, Colette Larre, Chiara Nitride, Rosa

Pilolli, Olivier Tranquet, et al.

\section{To cite this version:}

E.N. Clare Mills, Karine Adel-Patient, Herve H. Bernard, Marc de Loose, Nathalie Gillard, et al.. Detection and quantification of allergens in foods and minimum eliciting doses in food-allergic individuals (Thrall). Journal of AOAC INTERNATIONAL, 2019, 102 (5), pp.1346-1353. 10.5740/jaoacint.190063 . hal-02628572

\section{HAL Id: hal-02628572 \\ https://hal.inrae.fr/hal-02628572}

Submitted on 26 May 2020

HAL is a multi-disciplinary open access archive for the deposit and dissemination of scientific research documents, whether they are published or not. The documents may come from teaching and research institutions in France or abroad, or from public or private research centers.
L'archive ouverte pluridisciplinaire HAL, est destinée au dépôt et à la diffusion de documents scientifiques de niveau recherche, publiés ou non, émanant des établissements d'enseignement et de recherche français ou étrangers, des laboratoires publics ou privés.

\section{(1)(1) $\$(0)$}

Distributed under a Creative Commons Attribution - NonCommercial - ShareAlikel 4.0 


\section{Detection and Quantification of Allergens in Foods and Minimum Eliciting Doses in Food-Allergic Individuals (ThRAll)}

\section{E.N. Clare Mills}

The University of Manchester, Manchester Institute of Biotechnology, Manchester Academic Health Science Centre, School of Biological Sciences, Division of Infection, Immunity and Respiratory Medicine, Manchester, United Kingdom

Karine Adel-Patient and Hervé Bernard

INRA-CEA, Service de Pharmacologie et d'Immunoanalyse, Laboratoire d'Immuno-Allergie Alimentaire, Bât, 136-CEA de Saclay, 91191 Gif-sur-Yvette, France

MARC De Loose

Flanders Research Institute for Agriculture, Fisheries and Food, Brusselsesteenweg 370, 9170 Melle, Belgium

Nathalie Gillard and AnNe-Catherine Huet

CER Groupe, Rue du point du Jour, 8, 6900 Marloie, Belgium

COLletTe LARRÉ

UR1268 BIA, Rue de la Géraudière, BP 71627, 44316 Nantes, France

Chiara Nitride

The University of Manchester, Manchester Institute of Biotechnology, Manchester Academic Health Science Centre, School of Biological Sciences, Division of Infection, Immunity and Respiratory Medicine, Manchester, United Kingdom

Rosa Pilolli

National Research Council of Italy (CNR-ISPA), Institute of Sciences of Food Production, via Giovanni Amendola 122/O - 70126 Bari, Italy

Olivier Tranquet

UR1268 BIA, Rue de la Géraudière, BP 71627, 44316 Nantes, France

Christof Van Pouke

Flanders Research Institute for Agriculture, Fisheries and Food, Brusselsesteenweg 370, 9170 Melle, Belgium

Linda MonaCI

National Research Council of Italy (CNR-ISPA), Institute of Sciences of Food Production, via Giovanni Amendola 122/O - 70126 Bari, Italy

Risk-based approaches to managing allergens in foods are being developed by the food industry and regulatory authorities to support food-allergic consumers to avoid ingestion of their problem food, especially in relation to the traces of unintended allergens. The application of such approaches requires access to good quality data from clinical studies to support identification of levels of allergens in foods that are generally safe for most food-allergic consumers as well as analytical tools that are able to quantify allergenic food protein. The ThRAll project aims to support the application of risk-based approaches to food-allergen management in two ways. First, a harmonized quantitative MS-based prototype reference method will be developed for the detection of multiple food allergens in standardized incurred food matrices. This will be undertaken for cow's milk, hen's egg, peanut, soybean, hazelnut, and almond incurred into two highly processed food

Guest edited as a special report on "Mass Spectrometry: Status Quo in Food Allergen and Food Authenticity Applications" by Bert Popping and Carmen Diaz-Amigo.

Corresponding author's e-mail: clare.mills@manchester.ac.uk

DOI: https://doi.org/10.5740/jaoacint.19-0063 matrices, chocolate and broth powder. This activity is complemented by a second objective to support the development and curation of data on oral food challenges, which are used to define thresholds and minimum eliciting doses. This will be achieved through the development of common protocols for collection and curation of data that will be applied to allergenic foods for which there are currently data gaps.

I mmunoglobulin E (IgE)-mediated food allergies are estimated to affect almost $1 \%$ of the European population, with a wide geographic variation across the continent and rates higher in Northern Europe (1). They are characterized by a range of symptoms affecting the skin, respiratory, and gastrointestinal systems that usually appear within $2 \mathrm{~h}$ of consuming a food toward which an individual is allergic. In some instances, individuals can experience severe, life-threatening reactions known as anaphylaxis, which can be fatal (2). In the United Kingdom, IgE-mediated food hypersensitivity is responsible for $65 \%$ of hospitalizations because of adverse reactions to food, and from 1992 to $2012,86 \%$ of fatal reactions were caused by reactions to a combination of prepacked and catered foods, with young adults being especially vulnerable (2). Data from the European network of severe allergic reactions (3) has also shown that food 
is an important cause of severe reactions in children under the age of 18 years, causing $68 \%$ of incidents, while in adults, it was the third most important item, causing around $20 \%$ of incidents. The most important causative food was peanut followed by wheat, hazelnut, hen's egg, and cow's milk.

The lack of an accepted treatment for food allergy means patients have to practice avoidance of their problem food, often life-long for foods such as peanut and tree nuts, which, unlike allergies to milk and egg, are not usually outgrown in childhood. Those at risk of severe reactions are given rescue medication such as antihistamines and self-injectable adrenaline to use should they accidentally eat the food they are allergic to. Consequently, having a food allergy adversely affects a patient's quality of life as well as their families and carers (4). In order to help individuals avoid the foods to which they are allergic, the Codex Alimentarius Commission recommended that selected "priority" allergenic foods be declared on food labels irrespective of the level at which they are included in a recipe (5). This has subsequently been enacted in legislation across the world. In the European Union (EU), the original Codex list has been elaborated and now includes 14 different foods listed in Annex II of the food information for consumer's regulation [European Regulation No. 1169/2011; Food Information for Consumers Regulation (FIR)]. This includes the plant foods such as peanut, soybean, celery, mustard, sesame, lupin, tree nuts (hazelnut, walnut, pecan, pistachio, cashew, Brazil nut, almond, and Macadamia nut) and the animal-derived foods milk, egg, fish, and crustacean and molluscan shellfish. A recent amendment (Commission-delegated regulation No. 78/2014) replaced the introductory sentence in Annex II to classify Kamut and spelt as types of wheat. A commission notice of 13.07.2017 provided further revisions to Annex II. The notice specifies the definition of egg and milk to include all farmed birds and mammary gland farmed animals. Cereals containing gluten have to be described using a clear reference to the species.

Mandatory allergen labeling has helped allergic consumers avoid eating foods to which they are allergic. However, there remain uncertainties regarding the accidental contamination of foods with allergenic ingredients not declared in the ingredient label, which may occur through, for example, the use of common food-processing lines. This is because in practice it is not possible to exclude allergens completely from foods that are otherwise free from a particular allergenic ingredient when shared facilities and processing lines are used. As a result of such unintended allergen presence, precautionary allergen labels (PAL) are often applied to warn consumers of the potential risks such allergens pose (6). In 2011, the United Kingdom Food Standards Agency (FSA) performed a survey aiming to identify and quantify the unintended presence of milk, hazelnut, gluten, and peanut in commercial food products using ELISA technologies and correlate it to the correct use of PAL (7). The survey showed that, despite having no indication of the presence of milk and gluten in the ingredient list and not carrying a PAL, 3.3 and $2.1 \%$ of commercial food products contained gluten and milk, respectively. Among the confectionary products, dark chocolate was the most likely to have detectable levels of milk and hazelnut allergens, which was attributed to the manufacturing of milk and dark chocolate, with or without hazelnut, on the same production line (7). A similar survey of 351 food products, including chocolate/candy, bakery products, readyto-eat meals, meat, and fish products, was undertaken by the control authorities in Denmark, Finland, Norway, and Sweden in 2015 (8). This showed that $10 \%$ of the products were not correctly labeled, with the $3.2 \%$ having a list of ingredients that did not match the recipe and allergens not being highlighted on $18 \%$ of products. Analysis for milk, egg, hazelnut, peanut, and gluten showed milk was the most common undeclared food allergen in confectionary products and bakery products, while chocolate products carrying PAL were found to contain levels of hazelnut (3.1-18500 ppm), milk (2.7-8800 mg casein $/ \mathrm{kg})$, and peanuts $(0.7-42500 \mathrm{ppm})$ that would cause an allergic reaction in $50 \%$ of the population allergic to that food (8). The problems that allergens pose to the food industry are further emphasized by an analysis of the Rapid Alert System for Food and Feed database for the period 2011-2014 undertaken in the integrated approaches to food allergen and allergy management (iFAAM) project (9). This found that the unintended presence of milk $(29 \%)$ was the primary cause of allergen recalls, followed by cereal containing gluten $(16 \%)$, soy beans $(9 \%)$, tree nuts ( $8 \%$, including hazelnut and almond), egg ( $8 \%)$, and peanut $(4 \%$; $7)$. Cereals and bakery products $(27 \%)$ were the most frequently reported allergen-recalled products, followed by ready-to-eat meals, confectionary, and "soups, broths, sauces, and condiments" occurring in 21,9 , and $7 \%$, respectively. The definition of confectionary, cocoa, and bakery products caused difficulties for the analysis because some products, such as chocolate cookie and chocolate muffin mix, appeared to be listed under one category or the other arbitrarily. A further critical analysis of the FSA Food Alerts database from 2011 until 2014 indicated milk $(24 \%)$ as the primary cause of allergen recalls in the United Kingdom, followed by cereal containing gluten (19\%), tree nuts $(8 \%)$, peanut $(7 \%)$, and egg $(5 \%)$.

In order to help the industry apply PAL in a transparent manner, risk-assessment approaches have been developed in Australia by the Voluntary Incidental Trace Allergen Labelling (VITAL ${ }^{\mathrm{TM}}$ ) program (10) and the EU-integrated project iFAAM, which developed a tiered risk-assessment strategy. Both approaches are based on dose distribution data obtained from oral food challenges undertaken in food-allergic subjects and are currently based on the reference doses identified by the VITAL Scientific Expert Panel. The iFAAM project partnership identified data gaps; notably, there is a complete lack of threshold data for many tree nut species included on Annex 2 of the EU Food Information for Consumers regulation (i.e., pecan, pistachio, cashew, Brazil nut, Macadamia nut), different species of fish, and crustacean and molluscan shellfish. In order to provide the most reliable reference doses, more than 60 subjects should be included and challenged with appropriate doses (11). Accurate reference doses are available for only six foods: peanut, hazelnut, celery, shrimp, egg, and milk (10). Other data gaps include the effect of subject age and the problem that for some allergens, data may originate largely from a single clinical center (e.g., cashew). Some of the data used by the VITAL Scientific Expert Panel had a restricted geographic origin, although this may also reflect the prevalence of an allergy [e.g., subjects reacting to celeriac (celery spice) largely originated from Switzerland]. Selection bias in the patient populations undergoing challenges is also a concern with the possibility of individuals with a history of severe reaction being excluded from challenge because of safety concerns. However, the majority of studies and hospitals included in the VITAL assessment did not exclude individuals with a history of severe reactions. Studies such as immunotherapy clinical trials may also introduce bias through skewed selection of patients reacting at certain 
doses as part of their inclusion criteria. These concerns can best be addressed by continuing to collect data from worldwide clinical centers and comparing dose distributions of groups based on different selection criteria.

\section{Analytical Tools to Support Food-Allergen Management}

Tools that are able to effectively determine the levels of allergenic food protein(s) are essential for the effective implementation of food allergen quality assurance across the supply chain. These are needed to monitor either factory cleaning, ingredients, or finished products. The increasing use of risk-assessment methods for allergen management is driving the requirement for analytical readouts to be presented in milligrams total allergenic protein per kilogram of food rather than on a commodity basis. This is because the reference doses of allergenic foods on which risk assessments are based are derived from dose distributions modeled using data from threshold studies in allergic patients, undertaken using total allergenic ingredient protein as the potency measure. Concerns about the use of PAL led to a stakeholder workshop facilitated by the Joint Research Centre with Directorate-General for Health and Food Safety (DG Santé) on the "harmonisation of approaches for informing EU allergen labelling legislation." (12). As stated in the workshop report, "Possible agreement on analytical marker(s) and their conversion to a common reporting unity should be encouraged. The most appropriate reporting unit for reporting analytical results is $\mathrm{mg}$ total allergenic ingredient protein per kg food." Embedding analysis within a risk-assessment framework also brings clarity regarding the sensitivity required for allergen-detection methods. For example, according to the VITAL reference doses, analytical methods need to quantify food allergen protein in the milligram per kilogram range, with the concentration varying with the serving size. For example, a serving size of $50 \mathrm{~g}$ will require a method to be able to quantify egg protein at a level of $0.6 \mathrm{mg} / \mathrm{kg}$, hazelnut or milk proteins of $2 \mathrm{mg} / \mathrm{kg}$, and peanut proteins at $4 \mathrm{mg} / \mathrm{kg}$.

In the light of such considerations and because the protein component of allergenic foods is the hazardous fraction that is responsible for eliciting allergic reactions, the preferred methodology for allergen determination is one that detects this component. For this reason, immunoassay, particularly in the form of ELISA, is currently the preferred method. DNA-based methods using PCR assays, although not directly measuring the hazard (i.e., the protein), are also used for allergen detection. They provide a valuable alternative for those foods for which no ELISA-based test is available or for food matrices that render the allergen undetectable by ELISA. Furthermore, its multiplexing capacity makes it highly effective in screening multiple allergenic foods such as peanuts and tree nuts. However, the performance of both types of methods can be highly variable and matrix dependent, making results difficult to understand and interpret, and many have undergone only limited validation. The performance of immunological methods (ELISA and lateral-flow devices) can be adversely affected by issues of cross-reactivity (false positives), hook effects (false negatives), and extensive food processing $(13,14)$. Processing-induced modification of allergens (such as conformational changes, aggregation, and Maillard modifications) and the physical form of allergenic ingredients (powder, liquid, pasta) together with the nature of the food matrix are a major cause of test method variability. This is because they can modify allergen extractability from foods, adversely affect their recognition by antibody-based methods, or impair the recovery of DNA from samples (15). The performance of PCR-based methods can also be adversely affected by issues of interference and enzyme inhibitors (giving rise to false negatives) and poor DNA recovery from samples. The variability in test results, in turn, makes the validation of food-allergen management plans and monitoring of their implementation an uncertain process. In addition, there is a lack of consensus regarding reporting units, with many ELISAs reporting in allergenic commodity per kilogram of food product, and in these cases, a conversion to milligrams of total ingredient protein is required to allow analytical results to be used in allergen risk-assessment and management plans. For PCR assays, it is also difficult to convert from DNA copy number per microliter to milligram of allergenic protein.

The lack of metrologically traceable analytical results regarding the presence and quantity of allergenic foods means ELISA and PCR-based methods both fall short of the performance expected of reference methods, which are used, for example, in legal cases of dispute. EU legislation does not explicitly define the concept of "reference method" for food allergen measurements. However, performance criteria on analytical methods and interpretation of data to implement Council Directive 96/23/EC on measures to monitor certain substances and residues thereof in live animals and animal products has been published. This includes specific criteria for LC-MS analysis, benchmarking the methodology as having the characteristics expected of a reference method. In particular, MS methods based on selection reaction monitoring (SRM) have the potential to offer an alternative to ELISA and PCR for allergen analysis. In theory, such methods have the multiplexing capacity required for a multiallergen screening tool and the potential to provide a rigorous, orthogonal reference method for allergen analysis. The target quantification of signature peptide(s) as a surrogate marker for the precursor protein using LC-MS technology has several proven advantages, including specificity, sensitivity, and a broad dynamic range that may span four or five orders of magnitude (16). The approach can be quantitative when the isotopically labeled form of the target analyte is used as an internal standard. The isotopic peptides are identical in physicochemical structure, chromatographic performance, and ionization efficiency to the corresponding endogenous peptide despite their difference in mass of 5-6 Da (17). This helps to mitigate the effect of instrumental fluctuation, such as interference in SRM ion transition and signal suppression caused by matrix components, because only the relative intensities of the peak area of the natural peptide compared with peak area of the isotopically labeled peptides are determined, the latter being added to the sample at a gravimetrically determined known concentration. A calibration curve using the known concentration of the synthetic analogue of the signature peptides is used to determine the concentration of the unknown natural peptide. While mass spectrometers and chromatographic systems from different vendors can provide different measured responses (18), the use of common calibrants as well as the peptide ratio measurement can both allow measurements made in different laboratories, under different conditions and using different equipment, to be compared. More importantly, the use of labeled molecular analogues in targeted MS analysis provides traceable results (19). 
Despite these advantages, the application of MS to food allergen analysis is in its infancy, and efforts to realize its potential have revealed some limitations. For example, protein MS relies on access to repositories of protein sequences, which are largely derived from genomes to allow protein identification, but in general, there is a lack of such sequences for allergenic foods, especially those of plant origin. When genome sequences are available, they may not be in a format suitable for protein identification. Furthermore, species-specific peptide markers need to be identified, which also have the required performance characteristics to act as reporters (20). There can also be issues of sensitivity, although this may relate to the efficiency of the protein extraction and protease digestion steps rather than the actual peptide analysis. Relatively few of the proposed methods have been developed and validated using incurred samples despite the acknowledged importance of using such foods for allergen assay validation $(21,22)$. Thus, the effects of food processing on target protein stability and extractability, and on the resulting marker peptide selection and detectability, is often neglected. Processing-induced changes, such as the Maillard modification, block tryptic cleavage sites, and other food components such as polyphenols may cause ion suppression; furthermore, low $\mathrm{pH}$ foods or acid hydrolysis employed in preparation of functional ingredients may result in deamidation. These all have the potential to adversely impact MS-method sensitivity. A number of approaches to improve sensitivity have been explored, such as filter-aided digestion and online and offline pre-enrichment procedures making use of solid-phase extraction $(13,23-28)$.

\section{Developing a Prototype Reference Method for Determination of Allergens in Foods}

Given the need for a reference method for food allergen analysis, the ThRAll project partnership will focus on the development of MS-based multiple-reaction monitoring methods for the simultaneous detection and quantification analysis of allergens. The activity will focus on six foods [cow's milk, soybean, tree nuts (hazelnut, almond), hen's egg, and peanut] included on Annex II of the FIR, which are recognized as causing severe IgE-mediated reactions $(2,3)$, are representative of the major food allergens and food types responsible for recalls (9), and pose issues in foods carrying PAL $(7,8)$. Hazelnut and almond have been selected as representative allergenic tree nuts, which are widely used in food manufacturing and represent foods of public health importance in Europe causing severe reactions (3). Gluten has been excluded as a target analyte because it is primarily a problem for individuals with the gluten intolerance syndrome celiac disease and represents a sui generis (unique) target that presents many challenging issues regarding development of MS-based methods. This is because of the degenerate nature of the glutamine-repeat sequences and the lack of lysine residues, making gluten less amenable to classical tryptic digestion used in MS analysis of proteins $(29,30)$. The ingredients have been selected on the basis that they are representative of the foods as they are generally consumed and sourced from manufacturers that either only process that ingredient or are able to prevent cross-contact with other allergenic ingredients. They are as follows: Milk will be used in the form of skimmed milk powder (SMP) from cow (Bos taurus), as it is the form most widely used in food manufacturing, using the reference material from the MoniQA project (SMP-MQA 092014). Egg will be used in the form of spray-dried whole-egg reference material certified for its total protein content (NIST RM 8445). Again, this is a type of ingredient that is widely used in food manufacture. Peanut will be a lightly roasted, mechanically defatted peanut flour, which has also been used for collection of oral food challenge data $(31,32)$. Soybean will be sourced as full-fat soybean flour from a manufacturer solely handling soybean to reduce the chance of other allergens being present. The flour will not have been subjected to any thermal treatment and will retain its intrinsic enzyme activity. Hazelnut will be powdered ground hazelnut flour, such as that used for collection of oral food challenge data $(33,34)$. Almond will be sourced as blanched ground almonds, and like soybean, from a manufacturer solely handling almonds to reduce the chance of other allergens being present.

The allergenic ingredients will then be incurred into two matrices, a chocolate bar and a broth powder, prior to processing. The materials will be prepared in a food-processing pilot plant, mimicking conditions found in real processing lines as close as possible. A blank and a high-dose matrix will be produced and blended to prepare materials containing low levels of total commodity protein $(2,4,10$, and $40 \mathrm{mg}$ of protein $/ \mathrm{kg}$ ). Each of these matrices presents challenges for allergen analysis and are representative of the major food types responsible for recalls (baked goods, confectionary products, and complex multiphase foods). Thus, the chocolate matrix is both high in fat and polyphenols, while the broth powder is an extensive processed food matrix with a complex protein background from which the allergenic proteins will need to be discriminated. The homogeneity of the incurred allergens will be assessed using immunoassays and then used to develop a harmonized quantitative MS-based prototype reference method for the detection of multiple food allergens.

A crucial aspect of targeted MS method development is the selection of proteotypic peptides that act as markers for the presence of the allergenic protein. Such peptide markers must be specific to the particular allergenic food source and preferably originate from a recognized allergen molecule. In addition, the peptide markers must not include missed tryptic cleavage sites, be subject to post-translational modifications, or be prone to chemical modification and/or degradation during the protease digestion step used for sample preparation. This is because such features and modifications can reduce the yield of marker peptides and lead to the underestimation of the protein concentration. Therefore, an initial task of the project is to systematically review the peptide targets described in the published literature for the six allergenic food ingredients, taking into account factors that that might affect target peptide performance, such as (1) the matrix under investigation (composition and processing degree), (2) the allergenic ingredient used for the production of artificially contaminated matrices (e.g., whole/defatted, raw/roasted/ boiled ingredients, whole ingredient/its protein extract), and (3) whether the allergenic ingredient was incurred or if it was only spiked into a food matrix. The performance of the candidate peptides will then be verified and characterized by analysis of enzyme-digested extracts using untargeted LC-high-resolution-MS/MS analysis from which a preliminary list of candidate marker peptides will be identified (Figure 1).

Subsequently, the candidate peptide markers will be evaluated regarding the efficiency and reproducibility of being produced 


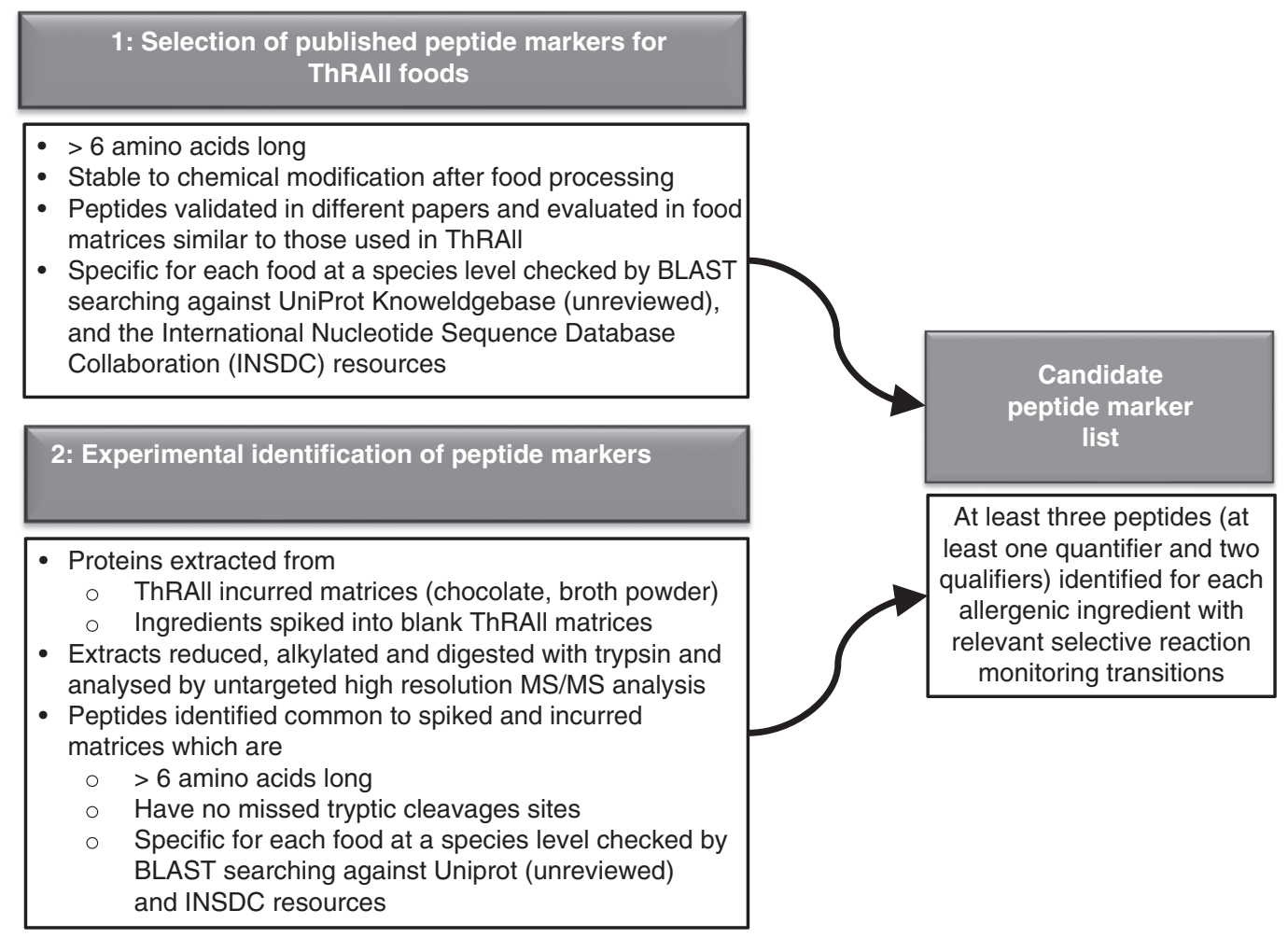

Figure 1. Identification of allergen peptide markers for selected cow's milk, hen's egg, peanut, soya, hazelnut, and almond.

from an allergenic food protein. This will be achieved by assessing the efficiency of extraction of the parent protein from a food, its enzymatic digestion to produce marker peptides, and the detection and quantification of those marker peptides. The resulting sample preparation and analysis protocols optimized for the selected allergen peptide targets will then be evaluated by the ThRAll project partner laboratories. These will be undertaken according to published guidelines (35) to allow calculation of LODs and quantitation limits together with method recovery, repeatability, and reproducibility under the optimized conditions. The acceptance performance criteria for quantitative methods listed in the Commission decision 2002/657/EC will be adapted to take account of requirements for MS methods for determining proteins in clinical assays $(18,36)$ together with those developed by, for example, AOAC INTERNATIONAL Standard Method Performance Requirement $\left(\mathrm{SMPR}^{\circledR}\right.$ 2016.002). These include retention time tolerance $(2.5 \%$ compared with the synthetic peptide), relative intensities of precursor/product ion pairs, and reproducibility (within laboratory and between laboratories). The aim of this exercise will be to identify a panel of peptides taking into account best practice (20); should it prove impossible to meet these criteria, at least three peptides (and a minimum of two) per allergenic food will be identified, each of which should preferably have three detectable transitions (one quantitative and two confirmatory transition per peptide) to achieve a robust method. Because of the lack of reference material certified for the amount of each allergenic protein, stable isotope-labeled forms of the peptides will be used as external calibrants and used to convert the molar quantity of the peptide detected in protein. This will be achieved by developing synthetic peptide calibration curves in blank matrix five to ten equidistant points to cover the range of concentrations incurred in the matrices.
The MS results will be compared with analytical results obtained on the same incurred materials using ELISA and PCR-based methods, allowing the performance of the candidate reference method to be set within the currently used methods. To enable this comparison, approaches will be developed to allow harmonization of test results, which will be expressed as milligrams of allergenic protein per kilogram food (Figure 2). Although reference material and common calibrants are ways in which harmonization can be achieved (37), such materials are still lacking for food allergens, and hence approaches previously applied to readouts in ring trials of ELISA methodologies will be used (38).

\section{Generating Good Quality Data on Minimum Eliciting Doses (MED) and Minimum Observed Eliciting Doses}

A second objective of the project is to address the issue of generating data for identifying MEDs of food allergens in food-allergic individuals. To date, the clinical community has focused on developing a consensus as to the way in which oral food challenges can be carried out in a safe manner with a view to making an unequivocal diagnosis (34). Projects such as EuroPrevall and iFAAM and nationally funded projects such as Maîtrise Allergènes NutritiOn Enfant and TRACE have worked to develop standardized protocols for collecting double-blind placebo-controlled food challenge (DBPCFC) data in multicenter studies to enable both confirmation of food allergy and provide data for defining MEDs (31-34). Building on clinical best practice for undertaking DBPCFC from the PRACTALL group (39) together with tools and approaches developed in the EuroPrevall and iFAAM projects (31-34), consensus approaches that support generation of good quality 


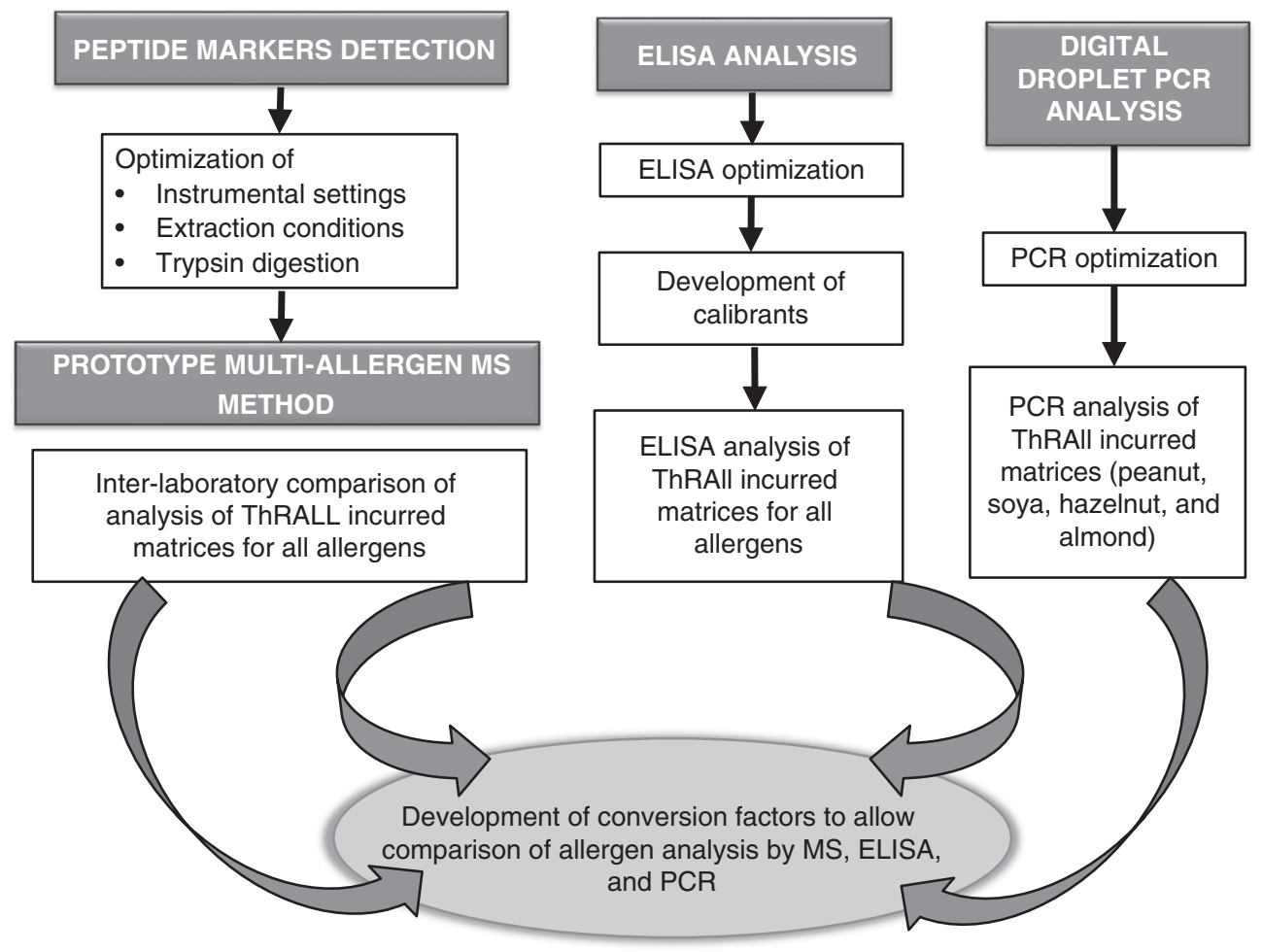

Figure 2. Flowchart representing the planned activities to deliver harmonized methodologies to detect and quantify allergens: (1) development of a prototype multiallergen MS method for allergens in complex matrices, (2) optimization of the ELISA analysis, and (3) development of digital droplet PCR for hazelnut, almond, peanut, and soy. Appropriate conversion factors will be generated to allow comparison.

data on MEDs from low-dose oral food challenges undertaken in food-allergic patients and quality assessment of data will be developed. These will then be applied to the analysis of existing data on foods for which gaps have been identified by the iFAAM project, notably tree nuts (walnut, cashew, pistachio, almond, and Macadamia nut), fish, and crustacean and molluscan shell fish. Where sufficient data are collected, dose distributions will be modeled using interval censoring survival analysis to calculate MEDs.

\section{Conclusions}

The ThRAll project builds on the multidisciplinary approaches that have underpinned much of the research undertaken to develop evidence-based approaches to food allergen management, such as EuroPrevall and iFAAM. $(40,41)$. It will achieve this by bringing together the development of analytical methods for allergen determination research relating to the clinical data required to support the identification of reference doses for food allergens that are considered safe for the majority of food-allergic individuals. Such multidisciplinarity is essential to ensure that analytical methods developed for allergens are clinically relevant by targeting allergenic molecules considered to be relevant for causing clinical reactions to foods, which are also capable of quantification at levels representative of candidate allergen reference doses. The availability of both reference methods for allergen analysis and tools for curation of threshold data to support identification of reference doses for allergens will contribute to building the toolbox required for effective allergen risk assessment and management. In this way, the ThRAll project outputs will support the food industry in, for example, appropriate application of PAL and thereby improve the safety of foods for food-allergic consumers.

\section{Acknowledgments}

This review was generated as part of the European Food Safety Authority project GP/EFSA/AFSCO/2017/03, "Detection and Quantification of Allergens in Foods and Minimum Eliciting Doses in Food Allergic Individuals," also cofounded by the United Kingdom Food Standards Agency and Belgian Federal Agency for the Safety of the Food Chain (FASFC). The present article, however, is under the sole responsibility of the authors. The positions and opinions presented in this article are those of the authors alone and do not necessarily represent the views or any official position or scientific works of EFSA. EFSA guidance documents and other scientific outputs of EFSA can be found in the EFSA website, http://www.efsa.europa.eu.

\section{References}

(1) Nwaru, B.I., Hickstein, L., Panesar, S.S., Roberts, G., Muraro, A., \& Sheikh, A. (2014) Allergy 69, 992-1007. doi:10.1111/all.12423

(2) Turner, P.J., Gowland, M.H., Sharma, V., Ierodiakonou, D., Harper, N., Garcez, T., Pumphrey, R., \& Boyle, R.J. (2015) J. Allergy Clin. Immunol. 135, 956-963.e1. doi:10.1016/j.jaci.2014.10.021

(3) Worm, M., Moneret-Vautrin, A., Scherer, K., Lang, R., Fernandez-Rivas, M., Cardona, V., Kowalski, M.L., Jutel, M., Poziomkowska-Gesicka, I., Papadopoulos, N.G., Beyer, K., Mustakov, T., Christoff, G., Bilò, M.B., Muraro, A., Hourihane, J.O.B., \& Grabenhenrich, L.B. (2014) Allergy 69, 1397-1404. doi:10.1111/all.12475 
(4) DunnGalvin, A., Dubois, A.E.J, Flokstra-de Blok, B.M.J., \& Hourihane, J.O'B. (2015) in Food Allergy: Molecular Basis and Clinical Practice, Vol. 101, M. Ebisawa, B.K. Ballmer-Weber, S. Vieths, \& R.A. Wood (Eds), Karger, Basel, Switzerland, pp 235-252. doi:10.1159/000375106

(5) Mills, E.N.C., Valovirta, E., Madsen, C., Taylor, S.L., Vieths, S., Anklam, E., Baumgartner, S., Koch, P., Crevel, R.W.R., \& Frewer, L. (2004) Allergy 59, 1262-1268. doi:10.1111/j.1398-9995.2004.00720.x

(6) DunnGalvin, A., Chan, C.H., Crevel, R., Grimshaw, K., Poms, R., Schnadt, S., Taylor, S.L., Turner, P., Allen, K.J., Austin, M., Baka, A., Baumert, J.L., Baumgartner, S., Beyer, K., Bucchini, L., Fernandez-Rivas, M., Grinter, K., Houben, G.F., Hourihane, J., Kenna, F., Kruizinga, A.G., Lack, G., Madsen, C.B., Mills, E.N.C., Papadopoulos, N.G., Alldrick, A., Regent, L., Sherlock, R., Wal, J.M., \& Roberts, G. (2015) Allergy 70, 1039-1051. doi:10.1111/all.12614

(7) Hirst, B. (2014) Advisory Labelling and Allergen Content of UK Retail Pre-Packed Processed Foods, https://www.food.gov.uk/ sites/default/files/media/document/survey-allergen-labellingprepacked.pdf

(8) Bolin, Y.S., \& Lindeberg, I. (2016) Undeclared Allergens in Food: Food Control, Analyses and Risk Assessment, Nordic Council of Ministers, Copenhagen, Denmark, https://norden. diva-portal.org/smash/get/diva2:934651/FULLTEXT03.pdf

(9) Bucchini, L., Guzzon, A., Poms, R., \& Senyuva, H. (2016) Food Addit. Contam. Part A 33, 760-771. doi:10.1080/19440049. 2016.1169444

(10) Taylor, S.L., Baumert, J.L., Kruizinga, A.G., Remington, B.C., Crevel, R.W., Brooke-Taylor, S., Allen, K.J., \& Houben, G. (2014) Food Chem. Toxicol. 63, 9-17. doi:10.1016/j.fct.2013.10.032

(11) Klein Entink, R.H., Remington, B.C., Blom, W.M., Rubingh, C.M., Kruizinga, A.G., Baumert, J.L., Taylor, S.L., \& Houben, G.F. (2014) Food Chem. Tox. 70, 134-143. doi:10.1016/j.fet.2014.05.001

(12) O'Connor, G., Haponiuk, M., \& Ulberth, F. (2017) Harmonisation of Approaches for informing EU allergen labelling legislation, JRC108259, Joint Research Centre, European Commission, Geel, Belgium, http://www.efanet.org/ images/2017/Newsltter10_2017-10_DG_Sante_DG_JRC_ Workshop_report_Geel_June_2016.pdf

(13) Parker, C.H., Khuda, S.E., Pereira, M., Ross, M.M., Fu, T.J., Fan, X., Wu, Y., Williams, K.M., DeVries, J., Pulvermacher, B., Bedford, B., Zhang, X., \& Jackson, L.S. (2015) J. Agric. Food Chem. 63, 10669-10680. doi:10.1021/acs.jafc.5b04287

(14) Khuda, S., Slate, A., Pereira, M., Al-Taher, F., Jackson, L., Diaz-Amigo, C., Bigley, E.C., Whitaker, T., \& Williams, K.M. (2012) J. Agric. Food Chem. 60, 4195-4203. doi:10.1021/jf3001839

(15) Poms, R.E., Capelletti, C., \& Anklam, E. (2004) Mol. Nutr. Food Res. 48, 459-464. doi:10.1002/mnfr.200400052

(16) Picotti, P., \& Aebersold, R. (2012) Nat. Methods 9, 555-566

(17) Koeberl, M., Clarke, D., \& Lopata, A.L. (2014) J. Proteome Res. 13, 3499-3509. doi:10.1021/pr500247r

(18) Abbatiello, S.E., Mani, D.R., Schilling, B., Maclean, B., Zimmerman, L.J., Feng, X., Cusack, M.P., Sedransk, N., Hall, S.C., Addona, T., Allen, S., Dodder, N.G., Ghosh, M., Held, J.M., Hedrick, V., Inerowicz, H.D., Jackson, A., Keshishian, H., Kim, J.W., Lyssand, J.S., Riley, C.P., Rudnick, P., Sadowski, P., Shaddox, K., Smith, D., Tomazela, D., Wahlander, A., Waldemarson, S., Whitwell, C.A., You, J., Zhang, S., Kinsinger, C.R., Mesri, M., Rodriguez, H., Borchers, C.H., Buck, C., Fisher, S.J., Gibson, B.W., Liebler, D., Maccoss, M., Neubert, T.A., Paulovich, A., Regnier, F., Skates, S.J., Tempst, P., Wang, M., \& Carr, S.A. (2013) Mol. Cell Proteomics 12, 2623-2639. doi:10.1074/mcp.M112.027078

(19) Walker, M.J., Burns, D.T., Elliott, C.T., Gowland, M.H., \& Mills, E.N.C. (2016) Analyst 141, 24-35. doi:10.1039/C5AN01457C
(20) Johnson, P.E., Baumgartner, S., Aldick, T., Bessant, C., Giosafatto, V., Heick, J., Mamone, G., O'Connor, G., Poms, R., Popping, B., Reuter, A., Ulberth, F., Watson, A., Monaci, L., \& Mills, E.N.C. (2011) J. AOAC Int. 94, 1026-1033

(21) Taylor, S.L., Nordlee, J.A., Niemannm, L.M., \& Lambrecht, D.M. (2009) Anal. Bioanal. Chem. 395, 83-92. doi:10.1007/s00216009-2944-0

(22) Monaci, L., De Angelis, E., Montemurro, N., \& Pilolli, R. (2018) Trends Anal. Chem. 106, 21-36. doi:10.1016/j.trac.2018.06.016

(23) Planque, M., Arnould, T., \& Gillard, N. (2017) in Allergen, S.S. Athari (Ed.), IntechOpen, Rijeka, Croatia. doi:10.5772/ intechopen.69361

(24) Sayers, R.L., Gethings, L.A., Lee, V., Balasundaram, A., Johnson, P.J., Marsh, J.A., Wallace, A., Brown, H., Rogers, A., Langridge, J.I., \& Mills, E.N.C. (2018) J. Prot. Res. 17, 647-655. doi:10.1021/acs.jproteome.7b00714

(25) Planque, M., Arnould, T., Dieu, M., Delahaut, P., Renard, P., \& Gillard, N. (2016) J. Chromatogr. A 1464, 115-123. doi:10.1016/j.chroma.2016.08.033

(26) Planque, M., Arnould, T., Renard, P., Delahaut, P., Dieu, M., \& Gillard, N. (2017) J. AOAC Int. 100, 1126-1130. doi:10.5740/jaoacint.17-0005

(27) Pilolli, R., De Angelis, E., \& Monaci, L. (2017) Food Chem. 221, 1747-1753. doi:10.1016/j.foodchem.2016.10.110

(28) Pilolli, R., De Angelis, E., \& Monaci, L. (2018) Anal. Bioanal. Chem. 410, 5653-5662. doi:10.1007/s00216-018-0927-8

(29) Bromilow, S.N., Gethings, L.A., Langridge, J.I., Shewry, P.R., Buckley, M., Bromley, M.J., \& Mills, E.N.C. (2016) Front Plant Sci. 7, 2020

(30) Martínez-Esteso, M.J., Nørgaard, J., Brohée, M., Haraszi, R., Maquet, A., \& O’Connor, G. (2016) J. Proteomics. 147, 156-168

(31) Ballmer-Weber, B.K., Fernandez-Rivas, M., Beyer, K., Defernez, M., Sperrin, M., Mackie, A.R., Salt, L.J., Hourihane, J.O’B., Asero, R., Belohlavkova, S., Kowalski, M., de Blay, F., Papadopoulos, N.G., Clausen, M., Knulst, A.C., Roberts, G., Popov, T., Sprikkelman, A.B., Dubakiene, R., Vieths, S., van Ree, R., Crevel, R., \& Mills, E.N.C. (2015) J. Allergy Clin. Immunol. 135, 964-971. doi:10.1016/j. jaci.2014.10.047

(32) Grabenhenrich, L.B., Reich, A., Bellach, J., Trendelenburg, V., Sprikkelman, A.B., Roberts, G., Grimshaw, K.E., Sigurdardottir, S., Kowalski, M.L., Papadopoulos, N.G., Quirce, S., Dubakiene, R., Niggemann, B., FernandezRivas, M., Ballmer-Weber, B., van Ree, R., Schnadt, S., Mills, E.N.C., Keil, T., \& Beyer, K. (2017) Allergy 72, 453-461. doi:10.1111/all.13049

(33) Fernandez-Rivas, M., Barreales, L., Mackie, A.R., Fritsche, P., Vazquez-Cortes, S., Jedrzejczak-Czechowicz, M., Kowalski, M.L., Clausen, M., Gislason, D., Sinaniotis, A., Kompoti, E., Le, T.M., Knulst, A.C., Purohit, A., de Blay, F., Kralimarkova, T., Popov, T., Asero, R., Belohlavkova, S., Seneviratne, S.L., Dubakiene, R., Lidholm, J., HoffmannSommergruber, K., Burney, P., Crevel, R., Brill, M., Fernandez-Perez, C., Vieths, S., Mills, E.N.C., van Ree, R., \& Ballmer-Weber, B.K. (2015) Allergy 70, 576-584. doi:10.1111/all.12585

(34) Cochrane, S.A., Salt, L.J., Wantling, E., Rogers, A., Coutts, J., Ballmer-Weber, B.K., Fritsche, P., Fernandez-Rivas, M., Reig, I., Knulst, A., Le, T.M., Asero, R., Beyer, K., Golding, M., Crevel, R., Mills, E.N.C., \& Mackie, A.R. (2012) Allergy 61, 107-113. doi:10.1111/j.13989995.2011.02715.x

(35) Koerner, T.B., Abbott, M., Godefroy, S.B., Popping, B., Yeung, J.M., Diaz-Amigo, C., Roberts, J., Taylor, S.L., Baumert, J.L., Ulberth, F., Wehling, P., \& Koehler, P. (2013) J. AOAC Int. 96, 1033-1040. doi:10.5740/jaoacint.13-043 
(36) Carr, S.A., Abbatiello, S.E., Ackermann, B.L., Borchers, C., Domon, B., Deutsch, E.W., Grant, R.P., Hoofnagle, A.N., Hüttenhain, R., Koomen, J.M., Liebler, D.C., Liu, T., MacLean, B., Mani, D.R., Mansfield, E., Neubert, H., Paulovich, A.G., Reiter, L., Vitek, O., Aebersold, R., Anderson, L., Bethem, R., Blonder, J., Boja, E., Botelho, J., Boyne, M., Bradshaw, R.A., Burlingame, A.L., Chan, D., Keshishian, H., Kuhn, E., Kinsinger, C., Lee, J.S., Lee, S.W., Moritz, R., Oses-Prieto, J., Rifai, N., Ritchie, J., Rodriguez, H., Srinivas, P.R., Townsend, R.R., Van Eyk, J., Whiteley, G., Wiita, A., \& Weintraub, S. (2014) Mol. Cell Proteomics 13, 907-917. doi:10.1074/mcp.M113.036095

(37) Rzychon, M., Brohée, M., Cordeiro, F., Haraszi, R., Ulberth, F., \& O'Connor, G. (2017) Food Chem. 234, 144-154. doi:10.1016/j.foodchem.2017.04.092

(38) Johnson, P.E., Rigby, N.M., Dainty, J.R., Mackie, A.R., Immer, U.U., Rogers, A., Titchener, P., Shoji, M., Ryan, A.,
Mata, L., Brown, H., Holzhauser, T., Dumont, V., Wykes, J.A., Walker, M., Griffin, J., White, J., Taylor, G., Popping, B., Crevel, R., Miguel, S., Lutter, P., Gaskin, F., Koerner, T.B., Clarke, D., Sherlock, R., Flanagan, A., Chan, C.H., \& Mills, E.N.C. (2014) Food Chem. 148, 30-36. doi:10.1016/j.foodchem.2013.09.115

(39) Sampson, H., Gerth van Wijk, R., Bindslev-Jensen, C., Sicherer, S., Teuber, S.S., Burks, A.W., Dubois, A.E., Beyer, K., Eigenmann, P.A., Spergel, J.M., Werfel, T., \& Chinchilli, V.M. (2012) J. Allergy Clin. Immunol. 130, 1260-1274. doi:10.1016/j.jaci.2012.10.017

(40) Mills, E.N.C., Mackie, A.R., Burney, P., Beyer, K., Frewer, L., Madsen, C., Botjes, E., Crevel, R.W., \& van Ree, R. (2007) Allergy 62, 717-722. doi:10.1111/j.1398-9995.2007.01425.x

(41) Nitride, C., Lee, V., Baricevic-Jones, I., Adel-Patient, K., Baumgartner, S., \& Mills, E.N.C. (2018) J. AOAC Int. 101, 83-90. doi:10.5740/jaoacint.17-0 $\overline{393}$ 